\title{
HUBUNGAN PENGALAMAN KERJA DAN ASUPAN KALORI DENGAN PRODUKTIVITAS KERJA PADA PEKERJA MEUBEL DI KABUPATEN MAJENE
}

\author{
${ }^{1}$ Zulkifli \\ ${ }^{1)}$ Prodi Diploma Keperawatan STIKes Bina Bangsa, Majene, Sulawesi Barat \\ E-mail: zulkifli.s.kep@gmail.com
}

\begin{abstract}
Abstrak
Produktivitas merupakan fungsi perkalian dari usaha pegawai (effor) yang didukung dengan motivasi yang tinggi dengan kemampuan pegawai (ability) yang di peroleh melalui latihan-latihan. Rumusan masalah dalam penelitian yaitu Hubungan pengalaman kerja dan asupan kalori dengan produktivitas kerja pada pekerja meubel di Kabupaten Majene. Tujuan penelitian untuk mengetahui hubungan pengalaman kerja dan asupan kalori terhadap produktivitas kerja pada pekerja meubel di Kabupaten Majene. Penelitian ini merupakan survey analitik dengan menggunakan metode pendekatan studi Cross Sectional. Populasi pada penelitian ini adalah pekerja meubel yang ada di Kabupaten majene. Sampel dalam penelitian ini sebanyak 31 responden dengan menggunakan Cluster Sampling. Tekhnik analisa data menggunakan uji kolmogorov-smirnov untuk mengetahui hubungan pengalaman kerja dan asupan kalori terhadap produktivitas kerja pada pekerja meubel di Kabupaten Majene. Berdasarkan hasil penelitian menunjukkan bahwa ada hubungan asupan kalori terhadap produktivitas nilai $\mathrm{p}=0,020<\alpha=0,05$. Ada hubungan asupan kalori terhadap produktivitas kerja meubel di nilai $\mathrm{p}=0,007<\alpha=0,05$. Sehingga dapat disimpulkan bahwa ada hubungan Asupan Kalori terhadap Produktivitas kerja pada pekerja meubel dan juga ada hubungan pengalaman kerja terhadap produktivitas kerja pada pekerja Meubel di Kabupaten Majene $\mathrm{P}<\alpha$. Disarankan kepada pemilik usaha industri meubel untuk memperhatikan menu makanan yang bervariasi dengan porsi makan yang sesuai dengan beban kerja untuk membantu mengatur produktivitas kerja
\end{abstract}

Kata kunci: Produktivitas kerja, asupan kalori, pengalaman kerja, pekerja meubel

\section{PENDAHULUAN}

Pengertian produktivitas sering dikacaukan dengan kata produksi. Produksi bukanlah produktivitas. Peningkatan produksi tidak selalu dengan peningkatan produktivitas karena dalam pengertian produksi yang menjadi perhatian adalah peningkatan output sedangkan penggunaan input kurang mendapatkan perhatian.

Gomes dalam Arif (2013) menyatakan bahwa produktivitas merupakan fungsi perkalian dari usaha pegawai (effort) yang didukung dengan motivasi yang tinggi dengan kemampuan pegawai (ability) yang diperoleh melalui latihan-latihan.

Data dari Badan Pusat Statistik (BPS) tahun 2003, pekerja di Indonesia mencapai 100. 316.007 di mana $64,63 \%$ pekerja laki-laki dan $35,37 \%$ pekerja wanita. Tingginya jumlah tenaga produktif ini belum diimbangi dengan perhatian pada status kesehatan dan gizi pekerja yang memadai yang dapat berakibat menurunnya produktivitas kerja dan ongkos produksi menjadi tidak efisien. 
Kondisi

perkembangan

pembangunan ke arah industrialisasi di mana persaingan pasar semakin ketat, sangat diperlukan tenaga kerja yang sehat dan produktif. Masyarakat pekerja mempunyai peranan dan kedudukan yang sangat penting sebagai pelaku dan tujuan pembangunan di mana dengan berkembangnya IPTEK dituntut adanya SDM yang berkualitas dan mempunyai produktivitas yang tinggi hingga mampu meningkatkan kesejahteraan dan daya saing di era globalisasi (Anonim, dalam Wardhani,2008).

World Health Organization (2011) menyatakan bahwa sebesar $45 \%$ atau 3.150 juta jiwa penduduk dunia adalah tenaga kerja. Diperkirakan dari jumlah tenaga kerja tersebut, sebesar 35\%$50 \%$ pekerja terpajan bahaya fisik, kimia, biologi dan juga bekerja dalam beban kerja fisik dan ergonomi yang melebihi kapasitasnya, termasuk beban psikologis serta stres.

\section{RANCANGAN PENELITIAN}

Desain Penelitian yang di gunakan adalah penelitian survey analitik penelitian penjelasan dengan menggunakan metode pendekatan studi Cross Sectional (seksional silang) di mana data yang menyangkut variabel independen dan dependen diteliti dalam waktu yang bersamaan kemudian diolah dan di analisis. Populasi adalah keseluruhan objek penelitian atau objek yang diteliti. Populasi dalam penelitian ini adalah semua pekerja meubel di
Kabupaten Majene jumlah populasi sebanyak 243 orang dari 8 kecamatan sebanyak 40 perusahaan.

Sampel merupakan sebagian yang diambil dari keseluruhan objek yang diteliti dan dianggap mewakili dengan jumlah sampel dari 2 kecamatan sebanyak 31 pekerja di 3 perusahaan dengan menggunakan teknik Cluster Sampling.

Teknik sampling berkelompok /daerah digunakan untuk menentukan sampel bila obyek yang akan diteliti atau sumber data sangat luas, misalnya penduduk suatu negara, propinsi atau kabupaten. Untuk menentukan penduduk mana yang akan dijadikan sumber data, maka pengambilan sampelnya berdasarkan daerah populasi yang telah ditetapkan (Wahab, 2013). Dari 8 Kecamatan yang ada di Kabupaten Majene di pilih 2 kecamatan yaitu Banggae dan Banggae Timur dari 2 kecamatan dipilih 3 industri meubel yang terdiri dari 31 pekerja/sampel

\section{HASIL}

1. Analisis Univariat

Hasil analisis univariat pada penelitian ini yang dilakukan pada 31 responden di Kabupaten Majene yaitu sebagai berikut :

\section{a. Umur}

Tabel 5.2

Distribusi Responden

Berdasarkan Umur Pekerja

di Perusahaan Meubel di

Kabupaten Majene 


\begin{tabular}{llll}
\hline No & Umur & N & $\%$ \\
\hline 1 & $20-25$ & 5 & 16,1 \\
2 & $26-30$ & 7 & 22,6 \\
3 & $31-35$ & 6 & 19,4 \\
4 & $36-40$ & 8 & 25,8 \\
5 & $41-45$ & 3 & 9,7 \\
6 & $46-50$ & 2 & 6,5 \\
\hline & Total & 31 & 100,0 \\
\hline
\end{tabular}

Sumber : Hasil Analisis, 2016

Berdasarkan Tabel 5.2 Menunjukkan bahwa umur responden yang paling banyak 36-40 tahun sebanyak 8 responden $(25,8 \%)$ dan yang memiliki umur paling sedikit 46-50 tahun sebanyak 2 responden $(6,5 \%)$.

\section{b. Pendidikan}

Tabel 5.3

Distribusi Responden Berdasarkan

Pendidikan Pekerja di Perusahaan Meubel di Kabupaten Majene

\begin{tabular}{llll}
\hline No & Pendidikan & $\mathrm{n}$ & $\%$ \\
\hline 1 & SD & 12 & 38,7 \\
2 & SMP & 8 & 25,8 \\
3 & SMA & 11 & 35,5 \\
\hline & Total & 31 & 100,0
\end{tabular}

Sumber : Hasil Analisis, 2016

Berdasarkan Tabel 5.3 Menunjukkan bahwa responden yang paling banyak adalah pada kategori Pendidikan SD sebanyak 12 responden $(38,7 \%)$ dan yang memiliki kategori pendidikan SMP sebanyak 8 responden $(25,8 \%)$. Dan yang memiliki tingkat kategori berpendidikan SMA/SMK sebanyak 11 responden $(35,5 \%)$

\section{c. Lama Kerja}

Tabel 5.4

\begin{tabular}{|c|c|c|c|}
\hline \multicolumn{4}{|c|}{$\begin{array}{c}\text { Distribusi Responden Berdasarkan } \\
\text { Lama Kerja Pada Pekerja di } \\
\text { Perusahaan Meubel di Kabupaten } \\
\text { Majene }\end{array}$} \\
\hline \multicolumn{4}{|c|}{$\begin{array}{llll}\text { Lama kerja } & \mathrm{N} & \% \\
\end{array}$} \\
\hline \multirow{3}{*}{\multicolumn{3}{|c|}{$\begin{array}{lll}1 & 8 \text { jam } & 17 \\
2 & 7 \text { jam } & 1 \\
& \text { Total } & 3\end{array}$}} & \multirow{2}{*}{$\begin{array}{l}54,8 \\
45,2\end{array}$} \\
\hline \multirow{2}{*}{2} & & & \\
\hline & & & 100,0 \\
\hline
\end{tabular}

Sumber : Hasil Analisis, 2016

Berdasarkan Tabel 5.4 menunjukkan bahwa responden dengan lama kerja 8 jam sebanyak 17 responden $(54,8 \%)$ dan responden yang dengan lama kerja 7 jam sebanyak 14 responden $(45,2 \%)$.

\section{d. Produktivitas Kerja}

Tabel 5.5

Distribusi Responden Berdasarkan Produktivitas kerja Pada Pekerja di perusahaan Meubel di Kabupaten Majene

\begin{tabular}{llll}
\hline No. & $\begin{array}{l}\text { Produktivitas } \\
\text { kerja }\end{array}$ & $\mathrm{n}$ & $\%$ \\
\hline 1 & Tinggi & 17 & 54,8 \\
2 & Sedang & 8 & 25,8 \\
3 & Rendah & 6 & 19,4 \\
\hline Jumlah & 31 & 100 \\
\hline
\end{tabular}

Sumber : Hasil Analisis, 2016

Berdasarkan Tabel 5.5 menunjukkan bahwa produktivitas kerja yang paling banyak terletak pada kategori tinggi yaitu sebanyak 17 responden $(54,8 \%)$ dan produktivitas kerja yang paling sedikit terletak pada kategori rendah yaitu sebanyak 6 responden $(19,4 \%)$

\section{e. Asupan Kalori}

Tabel 5.6 
Distribusi Responden Berdasarkan Asupan Kalori Pada pekerja di Perusahaan Meubel di Kabupaten Majene

\begin{tabular}{llll}
\hline No. & Asupan Kalori & $\mathrm{n}$ & $\%$ \\
\hline 1 & Memenuhi & 16 & 51,6 \\
2 & Tidak Memenuhi & 15 & 48,4 \\
\hline \multirow{2}{*}{ Jumlah } & 31 & 100
\end{tabular}

Sumber : Hasil Analisis, 2016

\section{Distibusi Hubungan \\ Produktivitas Kerja dengan \\ Asupan Kalori \\ pada pekerja Meubel di \\ Kabupaten Majene}

\begin{tabular}{|c|c|c|c|c|c|c|c|c|c|c|}
\hline \multirow{3}{*}{ No. } & \multirow{3}{*}{$\begin{array}{l}\text { Asupan } \\
\text { Kalori }\end{array}$} & \multicolumn{6}{|c|}{ Produktivitas kerja } & \multirow{2}{*}{\multicolumn{2}{|c|}{ Total }} & \multirow{3}{*}{ Nilai p } \\
\hline & & \multicolumn{2}{|c|}{ Tinggi } & \multicolumn{2}{|c|}{ Sedang } & \multicolumn{2}{|c|}{ Rendah } & & & \\
\hline & & $\mathrm{n}$ & $\%$ & $\mathrm{n}$ & $\%$ & $\mathrm{n}$ & $\%$ & $\mathrm{n}$ & $\%$ & \\
\hline 1 & Memenuhi & 13 & 81,2 & 2 & 12,5 & 1 & 6,2 & 16 & 100 & \\
\hline 2 & $\begin{array}{l}\text { Tidak } \\
\text { memenuhi }\end{array}$ & 4 & 26,7 & 6 & 40,0 & 5 & 33,3 & 15 & 100 & 0,020 \\
\hline
\end{tabular}

Berdasarkan Tabel 5.6 menunjukkan Sumber : Hasil Analisis, 2016

bahwa responden yang memiliki asupan kalori yang memenuhi sebanyak 16 responden $(51,6 \%)$ dan responden yang memiliki asupan kalori tidak memenuhi sebanyak 15 responden $(48,4 \%)$.

\section{f. Pengalaman kerja}

\section{Tabel 5.7}

Distribusi Responden Berdasarkan Pengalaman Kerja

Sumber : Hasil Analisis, 2016

Berdasarkan Tabel 5.7 menunjukkan

\begin{tabular}{lllcc}
\multicolumn{2}{l}{ bahwa } & pengalaman & kerja & yang \\
\hline No. & Pengalaman Kerja & $\mathrm{n}$ & $\%$ & \\
\hline 1 & Berpengalaman & 19 & 61,3 \\
2 & Tidak & 12 & 38,7 & \\
& Berpengalaman & & &
\end{tabular}

berpengalaman sebanyak 19 responden $(61,3 \%)$ dan responden yang tidak pengalaman sebanyak 12 responden $(38,7 \%)$.

2. Analisis Bivariat

Analisis Bivariat dalam penelitian ini menggunakan uji kolmogoro-Smirnov untuk mengetahui apakah ada hubungan antara asupan kalori terhadap produktivitas kerja pada pekerja meubel di Kabupaten Majene.

a. Hubungan produktivitas kerja dengan asupan kalori.

Tabel 5.8
Berdasarkan Tabel 5.8 menunjukkan bahwa sebanyak 16 responden yang memiliki asupan kalori yang memenuhi dan responden yang memiliki asupan kalori yang tidak memenuhi sebanyak 15 responden dalam bidang pekerjaan meubel dan masing-masing pekerja dengan kategori asupan kalori yang memenuhi sebanyak 13 responden $(81,2 \%)$ pada produktivitas kerja yang tinggi yang memenuhi asupan kalori sebanyak 1 responden $(6,2 \%)$ pada produktivitas kerja yang rendah. Tenaga kerja yang tidak memenuhi asupan kalori pada kategori produktivitas kerja sedang sebanyak 6 responden $(40,0 \%)$ dan responden yang memiliki asupan kalori yang tidak memenuhi dengan kategori produktivitas rendah sebanyak 4 responden $(26,7 \%)$.

Berdasarkan hasil uji statistik diperoleh nilai $\mathrm{p}<\alpha$ atau $0,020<0,05$ maka menolak Ho yang berarti bahwa terdapat hubungan produktivitas kerja dengan asupan kalori.

b. Hubungan Produktivitas Kerja dengan Pengalaman Kerja.

Tabel 5.9 


\section{Distirbusi Hubungan \\ Produktivitas Kerja dengan \\ Pengalaman \\ Kerja pada Pekerja Meubel \\ di Kabupaten Majene}

Sumber : Hasil Analisis, 2016

Berdasarkan Tabel 5.9 menunjukkan bahwa sebanyak 19 responden yang memiliki pengalaman kerja pada bidang pekerjaan meubel masing-masing pekerja dengan kategori produktivitas kerja tinggi berjumlah 15 responden atau $(78,9 \%)$, ada 3 responden $(15,8 \%)$ tingkat produktivitas kerja sedang, dan ada 1 responden $(5,3 \%)$ dengan kategori produktivitas kerja

\begin{tabular}{|c|c|c|c|c|c|c|c|c|c|c|}
\hline \multirow{3}{*}{ No } & \multirow{3}{*}{$\begin{array}{l}\text { Pengalaman } \\
\text { Kerja }\end{array}$} & \multicolumn{6}{|c|}{ Produktivitas kerja } & \multicolumn{3}{|c|}{ Total } \\
\hline & & \multicolumn{2}{|c|}{ Tinggi } & \multicolumn{2}{|c|}{ Sedang } & \multicolumn{2}{|c|}{ Rendah } & \multirow[b]{2}{*}{$\mathrm{N}$} & \multirow[b]{2}{*}{$\%$} & \multirow[t]{2}{*}{$\mathrm{p}$} \\
\hline & & $\mathrm{n}$ & $\%$ & $\mathrm{n}$ & $\%$ & $\mathrm{n}$ & $\%$ & & & \\
\hline 1 & Berpengalaman & 15 & 78,9 & 3 & 15,8 & 1 & 5,3 & 19 & 100 & \\
\hline 2 & $\begin{array}{l}\text { Tidak } \\
\text { Berpengalaman }\end{array}$ & 2 & 16,7 & 5 & 41,7 & 5 & 41,6 & 12 & 100 & 0,007 \\
\hline
\end{tabular}

rendah.

Sedangkan untuk 12 responden yang tidak berpengalaman di bidang pekerjaan meubel masing-masing bidang pekerjaan dengan kategori produktivitas kerja tinggi sebanyak 2 responden $(16,7 \%)$ ada 5 responden dengan tingkat produktivitas kerja sedang $(41,7 \%)$, dan ada 5 responden(41,6\%) dengan produktivitas kerja kategori rendah.

Berdasarkan hasil uji statistik diperoleh nilai $\mathrm{p}<\alpha$ atau $0,007<0,05$ maka menolak Ho yang berarti bahwa terdapat hubungan produktivitas kerja dengan pengalaman kerja.

\section{PEMBAHASAN PENELITIAN}

1. Hubungan Asupan Kalori dengan Produktivitas Kerja

Asupan kalori Gizi kerja adalah pemberian gizi yang diterapkan kepada pekerja dengan tujuan untuk meningkatkan derajat kesehatan efisiensi dan produktivitas kerja yang setinggitingginya. Sedangkan manfaat yang diharapkan dari pemenuhan gizi kerja adalah untuk mempertahankan dan meningkatkan ketahanan tubuh serta menyeimbangkan kebutuhan dan kalori terhadap tuntutan tugas pekerja (Tarwaka 2004).

Berdasarkan hasil analisis statistik dengan menggunakan uji kolmogorov-Smirnov terkait asupan kalori terhadap produktivitas kerja diperoleh ada hubungan produktivitas kerja dengan asupan kalori terhadap pekerja meubel yang ada di Kabupaten Majene dengan nilai $\mathrm{p}<\alpha$ atau $0,020<0,05$

Pekerja yang memiliki asupan kalori memenuhi standar kalori yang ditentukan akan tidak mudah lelah dalam melakukan pekerjaan, sedangkan pekerja yang memiliki asupan kalori yang tidak memenuhi standar yang ditentukan akan lebih mudah lelah dalam bekerja sehingga produktivitas dalam bekerja tidak seperti pekerja yang memiliki asupan gizi kalori yang cukup. Peraturan Menteri Ketenagakerjaan (1999) bahwa pemberian makan para pekerja seharusnya tiga kali makan utama dan dua kali selingan untuk memenuhi kebutuhan asupan kalori pekerja.

Di lokasi penelitian jenis makanan yang disediakan di perushaan meubel di Kecamatan Banggae Timur tepatnya di Kelurahaan Lembang II menu makanan yang disediakan oleh 
pemilik usaha bagi para pekerja seperti nasi, telur goreng ikan goreng, tahu, teri dan sayur bayam dan makanan selingan yang disediakan seperti kue donat, kopi. Dari tiga perusahaan meubel yang ada di di kabupaten majene dari dua kecamatan yang di jadikan tempat penelitian dari tiga tempat usaha industri meubel menu makanan yang disediakan hampir semua sama menu makanan yang disediakan untuk para pekerja oleh pemilik usaha.

Dari tiga usaha industri meubel di Kecamata Banggae dan Banggae Timur hanya ada sebagian pekerja yang pemberian makannya tiga kali diberi makan utama dan dua kali selingan dan sebagian hanya diberikan satu kali makan utama dan satu kali selingan. Tenaga kerja yang hanya diberi satu kali makanan utama dan satu kali selingan dengan tenaga kerja yang di beri makan tiga kali makan utama dan dua kali selingan akan berbeda jauh dalam melakukan suatu pekerjaan. Pekerja yang mendapatkan tiga kali makan utama dan dua kali selingan hanya pekerja yang tinggal di tempat usaha industri tersebut.

Secara garis besar di tempat penelitian pemberian makan para pekerja meubel untuk pemenuhan status gizi para pekerja terutama kebutuhan gizi kalori yang sangat di perlukan bagi tubuh para pekerja selama dalam melakukan aktivitas kerja sudah cukup baik, terutama di salah satu tempat perusahaan meubel yang ada di Kecamatan Banggae Timur pemberian makan untuk para pekerja tiga kali makan utama dan dua kali makanan selingan yang disediakan perusahaan meubel tepatnya di kelurahan lembang II sehingga sebagian para pekerja gizi kalori yang di konsumsi sudah tercukupi.

Gizi para pekerja yang ada di perusahaan tersebut sudah cukup baik terutama gizi asupan kalori agar para pekerja yang ada di perusahaan di bidang pekerjaan meubel berdampak baik bagi produktivitas kerja yang dilakukan. Gizi pada pekerja merupakan hal penting yang harus diperhatikan oleh pemilik perusahaan karena tercukupinya gizi selama bekerja akan dapat menambah energi bagi pekerja dan tidak mudah lelah dalam bekerja dan meningkatkan kapasitas kerja.

Gizi kerja adalah zat-zat gizi atau kalori yang diperlukan oleh tenaga kerja untuk memenuhi kebutuhan sesuai dengan kebutuhan pekerjaan. agar tidak mudah lelah dan produktivitas dalam bekerja tidak terganggu. Ini dikarenakan pemilik usaha sudah menyediakan makan para pekerja selama dalam melakukan aktivitas kerja selama 7-8 jam kerja sehari dan perusahaan meubel yang ada di Kecamatan Banggae sebagian sudah disediakan makanan selama dalam melakukan aktivitas kerja sehingga sebagian para pekerja tidak mudah lelah dalam melakukan aktivitas kerja dan akan berdampak baik bagi produktivitas kerja para pekerja industri meubel.

Gizi pada pekerja mempunyai peran penting, baik bagi 
kesejahteraan maupun dalam meningkatkan disiplin dan produktivitas. Oleh karena itu pekerja perlu mendapatkan asupan gizi yang cukup dan sesuai dengan jenis atau beban pekerjaan yang dilakukannya. Kekurangan nilai gizi pada makanan yang dikonsumsi tenaga kerja sehari-hari akan membawa akibat buruk terhadap tubuh, seperti: pertahanan tubuh terhadap penyakit menurun, kemampuan fisik kurang, berat badan menurun, kurang bersemangat, kurang motivasi dan lain sebagainya. Dalam keadaan yang demikian itu tidak bisa diharapkan tercapainya efisiensi dan produktivitas kerja yang optimal.

Penelitian ini sejalan dengan penelitian yang dilakukan Budianto yang dikutip dari Sujarweni(2015). Dari hasil uji Chi-Square diperoleh ada hubungan asupan energi pekerja dengan produktivitas kerja ( $p$ value 0,$021 ; p<0,05$ ) pada penjahit Sartika Express Kelurahan Sidodadi Kota Samarinda tahun 2015 dengan tingkat keeratan hubungan yang kuat sebesar 0,592 . Sesuai dengan (Sujarweni dalam Budianto 2015) diketahui bahwa phi $\quad(0,41-0,70) \quad$ dikatakan mempunyai keeratan yang kuat. Dimana asupan energi pekerja yang memiliki tingkat keeratan hubungan yang lebih kuat dengan produktivitas kerja dibandingkan dengan waktu kerja dengan lelah kerja.

2. Hubungan Pengalaman Kerja dengan Produktivitas Kerja
Berdasarkan hasil analisis statistik dengan menggunakan uji kolmogorov-Smirnov terkait hubungan pengalaman kerja terhadap produktivitas kerja diperoleh nilai $\mathrm{p}<\alpha$ atau $0,007<$ 0,05 maka menolak Ho yang berarti bahwa terdapat ada hubungan produktivitas kerja dengan pengalaman kerja terhadap pekerja meubel yang ada di Kabupaten Majene.

Pengalaman Kerja merupakan proses pembelajaran dan pertambahan perkembangan potensi bertingkah laku baik dari pendidikan formal maupun non formal atau bisa diartikan sebagai suatu proses yang membawa seseorang kepada suatu pola tingkah laku yang lebih tinggi. Suatu pembelajaran juga mencakup perubahan yang relatif tepat dari pelaku yang diakibatkan pengalaman, pemahaman (Haditono dalam Buranda, 2015).

Tenaga kerja yang berpengalaman dalam bekerja akan berbeda dengan orang tidak memiliki pengalaman kerja. Tenaga kerja yang banyak memiliki pengalaman kerja kemampuan kerjanya akan jauh lebih baik dari orang yang tidak memiliki pengalaman kerja, karena tenaga kerja yang berpengalaman akan belajar dari kegiatan-kegiatan dan permasalahan-permasalahan yang timbul dalam kerjanya dan akan lebih mudah melakukan suatu pekerjaan sehingga sangat berpengaruh terhadap produktivitas kerja. 
Responden yang memiliki pengalaman kerja luas maka akan berpengaruh terhadap produktivitas kerjanya karena akan mempunyai banyak pemikiran yang dalam melakukan suatu pekerjaan sehingga dapat menghasilkan produk yang memuaskan dan semakin terampil melakukan pekerjaan dan semakin sempurna pola berpikir sikap dalam bertindak untuk mencapai tujuan yang telah ditetapkan dan juga orang yang memiliki pengalaman kerja maka akan mudah mendapatkan pekerjaan yang baik karena adanya pengalaman kerja yang dimiliki.

Di lokasi penelitian
kebanyakan pekerja memiliki
pengalaman kerja yang baik
sehingga dalam membuat suatu
produk tidak diragukan lagi
melakukan pekerjaan dalam
membuat produk. Pekerja yang
berasal dari pulau Jawa dengan
bidang pekerjaan yang sama
sehingga para pekerja yang ada di
Mandar sendiri banyak belajar
kepada para pekerja yang berasal
dari pulau Jawa bahkan dalam
membuat suatu produk para pekerja
sangat mudah untuk mengeluarkan
ide yang baik dan keterampilan
dalam bekerja sehingga menunjang
pengembangan diri dan secara
tidak langsung berpengaruh
terhadap produktivitas kerja.
Penelitian ini sejalan dengan
pendapat (Puspaningsih dalam
Buranda, 2015) yang mengatakan
bahwa pengalaman kerja seseorang
menunjukkan jenis-jenis pekerjaan
yang pernah dilakukan seseorang

dan memberikan peluang yang besar bagi seseorang untuk melakukan pekerjaan yang lebih baik. Semakin luas pengalaman kerja seseorang, semakin terampil melakukan pekerjaan dan semakin sempurna pola berpikir sikap dalam bertindak untuk mencapai tujuan yang telah ditetapkan Orang yang berpengalaman dalam bekerja memiliki kemampuan kerja yang lebih baik dari orang yang baru saja memasuki dunia kerja, karena orang tersebut telah belajar dari kegiatan-kegiatan dan permasalahan yang timbul dalam kerjanya.

Pengalaman kerja mempunyai pengaruh terhadap banyaknya produksi besar kecilnya dan efisiensi yang dapat dilihat dari hasil produksi tenaga kerja yang diarahkan. Dalam pengertian lain, pengalaman kerja juga dapat diperoleh dengan melewati masa kerja yang telah dilakukan disuatu tempat kerja. Pengalaman kerja seseorang dalam suatu pekerjaan yang di manifestasikan dalam jumlah masa kerja akan meningkatkan kemampuan dan kecakapan kerja seseorang sehingga hasil kerja akan semakin meningkat.

Banyaknya jumlah pesanan secara tidak langsung memberikan kesempatan kepada tenaga kerja untuk menambah pengalaman kerja di mana secara keseluruhan tenaga kerja berdasarkan hasil observasi pekerja mampu menyelesaikan pesanan selama 1 minggu untuk satu set kursi dengan lama kerja 
setiap harinya adalah antara 7-8 jam kerja dalam sehari.

\section{KESIMPILAN DAN SARAN}

\section{A. KESIMPULAN}

Dari hasil penelitian tentang Hubungan pengalaman kerja dan asupan kalori dengan produktivitas kerja pada pekerja meubel di Kabupaten Majene yang di jadikan tempat penelitian adalah Kecamatan Banggae dan Kecamatan Banggae Timur, yang di lakukan pada tanggal 25 Juni sampai dengan 25 juli 2016 dengan jumlah sampel 31 sehingga dapat ditarik kesimpulan :

1. Ada hubungan Asupan kalori terhadap produktivitas kerja pada pekerja meubel di Kabupaten Majene.

2. Ada hubungan Pengalaman kerja terhadap produktivitas kerja pada pekerja meubel di Kabupaten Majene.

\section{B. Saran}

Adapun saran-saran yang bisa diberikan menyangkut penelitian ini adalah sebagai berikut :

1. Diharapkan Bagi pemilik usaha meubel perlu memperhatikan makanan yang disediakan para pekerja agar terpenuhinya gizi bagi pekerja, sehingga produktivitas pekerja bisa meningkat.

2. Untuk penelitian selanjutnya diharapkan memformulasikan model penelitian yang lebih komprehensif dalam mengungkap apa yang ada di balik fenomena produktivitas tenaga kerja karena dari hasil penelitian ini menunjukkan tenaga kerja masih banyak yang tidak memiliki pengalaman kerja khususnya di industri meubel sehingga bisa berdampak buruk pada perusahaan industri meubel akhirnya tidak dapat menghasilkan produksi barang yang baik sehingga tidak dapat memberikan kepuasan pada konsumen.

\section{DAFTAR PUSTAKA}

Arif ,Emilda, Faisal. 2013. Faktor Yang Mempengaruhi Produktivitas Tenagakerja Industri Kecil Kerajinan Mebel Pada Bagianproduksi Di Desa Tamansari Kecamatan Mumbulsari kabupaten Jember. Skripsi. Jember: Fakultas Ekonomi Universitas Jember. (online), (http://dspace.unej.ac.id/bitstream/ handle/123456789/5652/Emilda\%2 OFaisal\%20Arif\%20$\% 20080810191011 . p d f ?$ Sequence $=$ 1), di akses tanggal 26 april 2016.

Arikunto, Suharsimi. 2011. Pengumpulan Data Dan Instrumen Penelitian. (online), https://afidburhanuddin.wordpress.co $\mathrm{m} /$.../pengumpulan-data-daninstrumen-penelitia.) diakses 13 juni 2016.

Budianto, dkk. 2015. Hubungan Asupan Energi Pekerja Dan Waktu Kerja (http://www.fkmuwgm.ac.id/source/Journal\%20SITIAR A.docx). diaskses 11 agustus 2016.

Buranda, wiwik astuti. 2015. Analisis Faktor-Faktor Yang Mempengaruhi Produktivitas Tenaga Kerja Industri Kecil Di Kota Makassar. Skripsi. Makassar. Fakultas ekonomi dan bisnis. Universitas hasanuddin. 
(online),

(http://repository.unhas.ac.id/bitstream

/handle/123456789/14633/SKRIPSI\%

20LENGKAP-FEB-IE-

WIWIK\%20ASTUTI\%20BURANDA

.pdf?sequence $=1$ ), di akses tanggal 9 mei 2016.

Nadsif. 2015. Pengertian Meubel dan Forniture

(http://5302414086.blogspot.co.id/201

5/09/pengertian-mebel-dan

furniture.html) diakses 29 agustus 2016.

Muhibbang. 2014. Pengaruh Motivasi Dan

Pengalaman Kerja Terhadap

Produktivitas Kerja Karyawan

Pada PT. Bosowa Berlian Motor

Makassar. Skripsi. Makassar:

Fakultas Ekonomi dan Bisnis.

Universitas Hasanuddin.

(online),

Prasetyo, Alfi. 2014._Analisis faktor-faktor yang mempengaruhi produktivitas pada tenaga kerja. Skripsi. Malang : fakultas ekonomi dan bisnis universitas brawijaya malang. (online),

(https://jimfeb.ub.ac.id/index.php/ji mfeb/article/download/1278/1176o

leh APPdf Prasetyo - 2014,) diakses 20 april 2016.

Rimbano, Dheo.2014. Pengaruh Motivasi Dan Pengalaman KerjaTerhadap Produktivitas Karyawan Pada Master Group Cash Dan Credit kota Lubuklinggau. Jurnal. Ekonomi Dan Informasi Akuntansi (Jenius(online)

(Https://news.palcomtech.com/wpc ontent/uploads/2015/06/DHEO-

JE040114.pdf) diakses 1 juni 2016.
Septyaningrum, Hani. 2012. Studi intake energi (kalori) kerja di pt united tractors tbk tahun 2011.skripsi. Fakultas kesehatan masyarakat. Universitas indonesia. (online), (Http:// lib.ui.ac.id/file? File=digital/20291 346-S-

Hani\%20Septyaningrum.pdf) diakses 8 mei 2016. Statistical Product and Service Solutions 20

Sualaeman Ardika. 2014. Pengaruh Upah dan Pengalaman Kerja terhadap Produktivitas Karyawan Kerajinan Ukiran Kabupaten Subang. Trikonomika. (online). (Http://www.jurnal.fe.unpas.ac.id/o js/index.php/trikonomika/article/vi $\underline{\text { ewfile/94/96) }}$

Suyoso, Gandu Eko Juliato. 2013. Profil status gizi dan kebutuhan kalori karyawan pt. Pembangunan perumahan (pp) (persero) tbk proyek educity residence surabaya. Skripsi tidak di terbitkan. Surabaya: Fakultas Kesehatan Masyarakat. Universitas Airlangga.

Tarwaka. 2010. Ergonomi Industri. Surakarta: harapan Press Solo.

Tarwaka. 2015. Keselamatan, Kesehatan Kerja Dan Ergonomi (K3e) Dalam Perspektif Bisnis. Edisi Pertama. Surakarta: Harapan press.

Tarwaka. Dkk. 2004.

Ergonomi,Keselamatan Kerja.

Surakarta: uniba press.

Wahab, Abdul. 2013. Pengantar Riset. Bidang Kesehatan, Kebidanan dan 
Keperawatan. Edisi Pertama. Kaukaba Dipantara : Pangguharjo Sewon Bantul.

Wardhani, Movira Wuryanti. 2008. Hubungan gizi kerja dengan produktivitas Tenaga kerja wanita industri batik. Skripsi. Surakarta.

Pasca sarjana. Universitas Sebelas Maret.

(Https://core.ac.uk/download/files/ 478/12348556.pdf) diakses 20 april 2016. 